\title{
Plasticity and stability in recurrent neural networks
}

\author{
Friedemann Zenke*, Guillaume Hennequin, Henning Sprekeler, Tim P Vogels, Wulfram Gerstner \\ From Twentieth Annual Computational Neuroscience Meeting: CNS*2011 \\ Stockholm, Sweden. 23-28 July 2011
}

Over the past 30 years, Bienenstock-Cooper-Munro (BCM) [1] type learning rules have shaped our understanding of synaptic plasticity. While they excel at explaining the emergence of receptive fields and stimulus selectivity in networks with feed-forward architecture, their impact on recurrent scenarios is less distinctive.

Here, we analyze general BCM-type synaptic plasticity rules with a homeostatic sliding threshold in the framework of recurrent networks of rate-based and spiking neurons. We begin by considering the effects of learning rate and homeostatic timescales on network stability in a non-linear firing rate model. We show how a sensible choice of timescales leads to stable weight dynamics, but other seemingly sensible parameter choices will inevitably lead to catastrophic run-away potentiation. We discuss under which conditions a stable fixed-point in a regime of Hebbian learning exists.

We then study the network's response to perturbations and quantify the critical point whereupon network stability is compromised. By viewing perturbation as a consequence of pattern storage in synaptic connections, we quantify the number of such patterns that can be learned safely in a given time.

Our model could provide simple explanations as to why memory intake capacity is limited and why learning becomes increasingly inefficient during intensive learning periods. We confirm these findings in numerical simulations of spiking neural networks and show that our analytical results apply to synapses subject to additive triplet-STDP [2].

Published: 18 July 2011

* Correspondence: friedemann.zenke@epfl.ch

School of Computer \& Communication Sciences and Brain-Mind Institute, École Polytechnique Fédérale de Lausanne, 1015, Switzerland
References

1. Bienenstock $E$, Cooper $L$, Munro P: Theory for the development of neuron selectivity: orientation specificity and binocular interaction in visual cortex. Journal of Neuroscience 1982, 2(1):32-48.

2. Pfister J-P, Gerstner W: Triplets of spikes in a model of spike timingdependent plasticity. Journal of Neuroscience 2006, 26(38):9673-82.

doi:10.1186/1471-2202-12-S1-P120

Cite this article as: Zenke et al:: Plasticity and stability in recurrent neural networks. BMC Neuroscience 2011 12(Suppl 1):P120.
Submit your next manuscript to BioMed Central and take full advantage of:

- Convenient online submission

- Thorough peer review

- No space constraints or color figure charges

- Immediate publication on acceptance

- Inclusion in PubMed, CAS, Scopus and Google Scholar

- Research which is freely available for redistribution

\section{() Biomed Central}

C Biomed Central

ㄷ 2011 Zenke et al; licensee BioMed Central Ltd. This is an open access article distributed under the terms of the Creative Commons Attribution License (http://creativecommons.org/licenses/by/2.0), which permits unrestricted use, distribution, and reproduction in any medium, provided the original work is properly cited. 